\title{
CINÉTICA DE SECAGEM EM CAMADA FINA DA POLPA DE CLADÓDIOS DE PALMA FORRAGEIRA (Opuntia ficus indica Mill) EM ESTUFA COM CIR CULAÇÃO FORÇADA DE AR
}

\author{
G. M.V.MARTINS ${ }^{1}$, J.P.L.FERREIRA ${ }^{2}$, A. E. SANTOS ${ }^{3}$, R. S. NOBRE ${ }^{4}$ \\ 1,2, 3,4 Universidade Federal de Campina Grande, Centro de Ciências e Tecnologia A groalimentar \\ E-mail para contato: georgiana.82@gmail.com
}

RESUMO - Este trabalho foi realizado com o objetivo de estudar a secagem em camada fina da polpa do cladódio (broto) da palma forrageira (Opuntia ficus-indica Mill), desidratada em estufa com circulação forçada de ar, a 50; 60 e $70{ }^{\circ} \mathrm{C}$, com três diferentes espessuras da camada $(5 ; 5,5$ e $6 \mathrm{~mm}$ ). Com os dados obtidos durante o processo de secagem foram traçadas as curvas de secagem e ajustados aos modelos de Wang e Sing, Henderson e Pabis, A proximação da Difusão e Exponencial dois Termos. Para analisar os efeitos dos fatores na cinética de secagem da polpa do cladódio da palma forrageira, utilizou-se um planejamento experimental fatorial completo $2^{3}$ com 3 pontos centrais, sendo três fatores (temperatura, espessura e tempo), avaliados em dois níveis $(-e+)$, para constante de secagem ( $k$ ). Verificou-se que a espessura da camada e a temperatura de secagem influenciaram no tempo de secagem da polpa do cladódio da palma forrageira, sendo o processo mais rápido para a menor espessura da camada e maior temperatura. $O$ modelo de A proximação da Difusão foi o que melhor se ajustou as curvas de cinética de secagem da amostra.

\section{INTRODUÇÃO}

A palma forrageira, Opuntia fícus-indica (L.) Mill, cactácea exótica originária do México, está presente em todos os continentes com diversas finalidades, destacando-se sua utilização na alimentação animal, essa planta possui um enorme potencial produtivo e diversas outras utilidades, podendo ser utilizada para produção de medicamentos, cosméticos, recuperação de solos, culinária, entre outros. Desse modo, o conhecimento das propriedades físico-químicas da palma é importante para a caracterização do seu múltiplo uso (HOFFMANN, 1995; MOURA et al., 2009).

Os cladódios da palma, também conhecidos como broto de palma ou nopalitos, constituem-se numa boa fonte de mucilagem, fibras e minerais, sendo estes elementos importantes para a dieta humana (SA ENZ 1997, 2000). A lém disso, estudos recentes demonstram a viabilidade de processamento desta planta para obtenção de sucos, geléias, géis, adoçantes líquidos, picles, doces, molhos entre outros (SAENZ e COSTELL, 1990). Os cladódios de Opuntia ficus-indica também podem ser processados na forma de farinha (extrato seco), podendo ser utilizada como ingrediente alimentício em pequenas agroindústrias (SAENZ, 1997). 
Esta cactácea é bastante comum na região do sertão da Paraíba, no entanto poucos estudos foram realizados com esta planta para seu aproveitamento no consumo humano, já que vários produtos podem ser obtidos a partir da palma.

A secagem artificial é uma operação relativamente cara; entretanto, apresenta uma série de vantagens com relação à secagem natural, como independência das condições climáticas, possibilidade de se estabelecer um programa de operação com mais facilidade; além disso, diminui o risco de deterioração dos alimentos em função do tempo de secagem ser menor (SOUSA, 1999).

Durante muito tempo o tradicional método de secagem na agricultura era deixar o produto no campo, sob a ação do sol e do vento, para perder parte de sua umidade. Conforme o tempo foi passando e com os conhecimentos adquiridos pela experiência, os artesãos se foram tornando cada vez mais capazes de lidar com secagem e armazenamento de alimentos; atualmente, esses assuntos são objeto de estudos em muitos centros de pesquisa e universidades em todo o mundo, em um processo contínuo de descobertas de novas metodologias de otimização da economia e qualidade do produto (FIOREZE, 2004).

O presente trabalho teve como objetivo avaliar a influência da espessura da camada da polpa e da temperatura de secagem, no processo de secagem em camada fina da polpa do cladódio (broto) da palma forrageira.

\section{MATERIAL E MÉTODOS}

Os experimentos foram conduzidos no Laboratório de Tecnologia de Produtos Hortícolas (LTPH) do Centro de Ciência e Tecnologia A groalimentar (CCTA) da Universidade Federal de Campina Grande (UFCG). Utilizou-se como matéria-prima os brotos da palma forrageira (Opuntia fícus indica Mill) provenientes do campus da UEPB em Catolé do Rocha, PB.

Foram colhidos os brotos que apresentavam comprimento de $17 \mathrm{a} 21 \mathrm{~cm}$ de acordo com o Codex Alimentarius (2005). No laboratório, foram selecionados manualmente de forma a eliminar os exemplares que apresentavam danos físicos ou aspectos de podridão. Procedeu-se uma lavagem em água corrente, com seguida imersão em solução de hipoclorito de sódio a 50 ppm, durante 15 minutos; posteriormente, foi retirado o excesso de cloro (enxágüe) e escorrido o excesso de água. A pós a limpeza e sanitização, os brotos foram cortados com auxílio de facas de aço inoxidável em pequenos pedaços para facilitar sua trituração. A seguir os pedaços de broto foram triturados e homogeneizados em um processador, o material obtido foi transferido para bandejas de aço inoxidável, o qual foi uniformemente espalhado com espátula de aço inoxidável, compondo amostras com camadas de diferentes espessuras $(0,5 ; 0,55 ; 0,6 \mathrm{~cm})$, medidas com o auxilio de um paquímetro digital.

Antes do inicio da secagem se determinou o teor de água inicial do broto de palma, de acordo com A.O.A.C. (1997), que constitui em se submeter às amostras em estufa, a temperatura de $105^{\circ} \mathrm{C}+/-2^{\circ} \mathrm{C}$ durante 24 horas para permitir a retirada total da água. A Equação 1 foi utilizada para determinação do teor de água em base úmida.

$$
X_{B U}=\left(P_{i}-P_{f}\right) / P_{i}
$$


onde:

$X_{B U}$-teor de água em base seca

$P_{i}$ - peso inicial, em gramas

$P_{f}$-peso final, em gramas

Para determinação do teor de água em base seca, usou-se a Equação 2.

$X_{B S}=X_{B U} /\left(1-X_{B U}\right)$

onde:

$X_{B S}:$ teor de água em base seca

$X_{B U}$ : teor de água em base úmida

As amostras nas bandejas foram levadas para secagem em estufa com circulação de ar, nas temperaturas de 50; 60 e $70^{\circ} \mathrm{C}$. O experimento foi realizado em triplicata, sendo as pesagens do material realizada em balança analitica modelo SHIMADZU AY220, com máximo $220 \mathrm{~g} e$ mínimo 0,01g, até obtenção do equilíbrio.

Os dados da cinética de secagem foram obtidos pesando-se as bandejas com as amostras, durante as secagens, até peso constante, em intervalos regulares de tempo. Com os dados experimentais da secagem e utilizando a Equação 2, foram calculados os valores da razão de teor de água.

$$
R U=\left(U-U_{e}\right) /\left(U_{0}-U_{e}\right)
$$

onde:

$R U-$ razão de teor de água (adimensional)

$U$-teor de umidade "absoluta" (base seca)

$U_{e}$ - teor de umidade de equilibrio (base seca)

$U_{0}$ - teor de umidade inicial (base seca)

A análise e a representação dos dados experimentais do processo de secagem foram realizadas utilizando-se os modelos de Wang e Singh. Henderson e Pabis, Aproximação da Difusão e Exponencial dois Termos, que estão apresentados na Tabela 1. Os parâmetros dos modelos utilizados foram obtidos mediante aplicação dos dados experimentais a análise de regressão não-linear, pelo método Gauss-Newton no programa computacional STATISTICA, versão 5.0 .

Os Modelos matemáticos de regressão não linear, utilizados para predizer o fenômeno da secagem de polpa do broto da palma serão apresentados a seguir: 
Tabela 1 - Modelos matemáticos de regressão não linear, utilizados para predizer o fenômeno da secagem de polpa de palma

\begin{tabular}{|c|c|c|}
\hline Modelo & Equação & Referência \\
\hline Wang e Sing & $R U=1+a t+b t^{2}(4)$ & Silva et al (2009) \\
\hline Henderson e Pabis & $R U=a \exp (-k t)$ & Melo et al (2013) \\
\hline Arpoximação da Difusão & $R U=a \exp (-k)+(1-a) \exp (-k b t)(6)$ & Santos et al (2010) \\
\hline Exponencial dois Termos & $R U=a \exp (-k t)+(1-a) \exp (-k t)$ & (7) Silva et al (2009) \\
\hline
\end{tabular}

Em que: $R U$-razão de umidade do material, adimensional; $t$-tempo de secagem (min., $h$ ); a e bconstantes do modelo; $k$-constante de secagem $\left(\mathrm{min}^{-1}\right)$.

O processo de secagem convectiva da polpa do broto da palma foi estudado mediante planejamento experimental fatorial completo $2^{3}$ com 3 pontos centrais, sendo três fatores ou variáveis independentes (temperatura, espessura da camada e tempo), avaliadas em dois niveis ($e+$ ), para o fator ou variável de resposta constante de secagem (K). Na matriz de planejamento experimental, os valores das variáveis independentes estão representados na forma codificada (-1, 0 e +1) e real (temperatura: 50, 60 e $70^{\circ} \mathrm{C}$; espessura:5; 5,5 e $6 \mathrm{~mm}$; tempo de secagem: 8, 10 e 12 horas) sendo os fatores e os respectivos níveis apresentados na Tabela 2.

Tabela 2 - Matriz de planejamento experimental completo $\left(2^{3}\right)$ e 3 pontos centrais para constante de secagem $(K)$

\begin{tabular}{cccc}
\hline Ensaio & Temperatura $\left({ }^{\circ} \mathrm{C}\right)$ & $\begin{array}{c}\text { Espessura da camada } \\
(\mathrm{mm})\end{array}$ & $\begin{array}{c}\text { Tempo de secagem } \\
(\mathrm{h})\end{array}$ \\
\hline 1 & $-1\left(50^{\circ} \mathrm{C}\right)$ & $-1(5)$ & $-1(8)$ \\
2 & $+1\left(70^{\circ} \mathrm{C}\right)$ & $-1(5)$ & $-1(8)$ \\
3 & $-1\left(50^{\circ} \mathrm{C}\right)$ & $+1(6)$ & $-1(8)$ \\
4 & $+1\left(70^{\circ} \mathrm{C}\right)$ & $+1(6)$ & $-1(8)$ \\
5 & $-1\left(60^{\circ} \mathrm{C}\right)$ & $-1(5)$ & $+1(12)$ \\
6 & $+1\left(70^{\circ} \mathrm{C}\right)$ & $-1(5)$ & $+1(12)$ \\
7 & $-1\left(50^{\circ} \mathrm{C}\right)$ & $+1(6)$ & $+1(12)$ \\
8 & $+1\left(70^{\circ} \mathrm{C}\right)$ & $+1(6)$ & $+1(12)$ \\
9 & $0\left(60^{\circ} \mathrm{C}\right)$ & $0(5,5)$ & $0(10)$ \\
10 & $0\left(60^{\circ} \mathrm{C}\right)$ & $0(5,5)$ & $0(10)$ \\
11 & $0\left(60^{\circ} \mathrm{C}\right)$ & $0(5,5)$ & $0(10)$ \\
\hline
\end{tabular}




\section{RESULTADOS E DISCUSSÃO}

A Figura 1 representa as curvas de secagem da polpa do broto da palma em camada fina em diferentes temperaturas $\left(50,60\right.$ e $\left.70^{\circ} \mathrm{C}\right)$, espessura $(2,4$ e $6 \mathrm{~mm})$ e tempo de secagem $(8,10$ e 12 horas), seguindo a matriz experimental mostrada anteriormente.

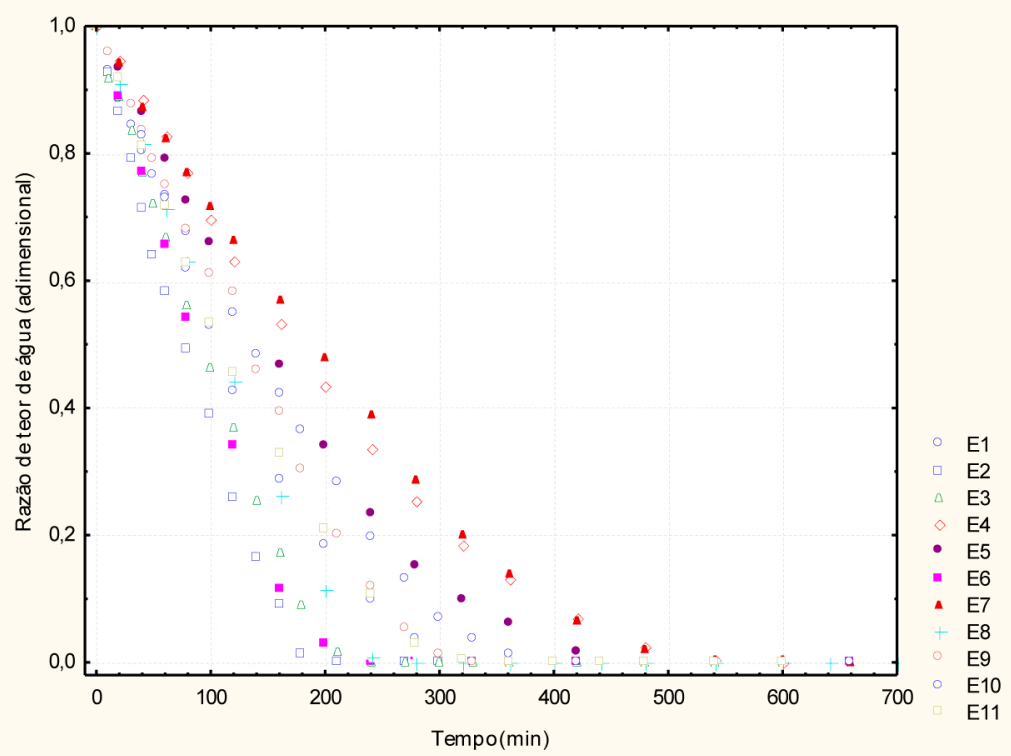

Figura 1 - Curvas da razão de umidade (RU) em função do tempo para as secagens da matriz experimental.

A nalisando as curvas de razão de umidade, demonstrada na Figura 1, verifica-se que o aumento da temperatura favorece o processo de transferência de energia na forma de calor para as amostras, conseqüentemente diminuindo o tempo necessário para a polpa do broto atingir o equilíbrio. Estes resultados estão de acordo com os estudos realizados por Silva et al (2009) para a secagem de banana maçã, com Y $i$ et al. (2012), estudando a cinética de secagem em camada fina e a modelagem matemática de jujuba chinesa. Corroborando com os resultados desta pesquisa também encontram-se os estudos realizados por Santos et al (2010) que estudou a secagem de banana terra e com o estudo de Sousa et al (2011) para a secagem da polpa do oiti nas temperaturas de 50,60 e $70^{\circ} \mathrm{C}$.

Na Tabela 3 são apresentados os valores dos coeficientes de determinação $\left(R^{2}\right.$, em \%) e o desvio quadrático médio (DQM, em decimal) para os quatros modelos analisados para as secagens da matriz experimental. 
Tabela 3 - Valores do coeficiente de determinação $\left(R^{2}\right)$ e do desvio quadrático médio $(D Q M)$, calculados para verificação do ajuste dos modelos matemáticos aos valores experimentais para as secagens da matriz experimental.

\begin{tabular}{ccccccccc}
\hline & & & \multicolumn{2}{c}{$\begin{array}{c}\text { Hendersone } \\
\text { Pabis }\end{array}$} & $\begin{array}{c}\text { Aproximação } \\
\text { da Difusão }\end{array}$ & $\begin{array}{c}\text { Exponencial dois } \\
\text { Termos }\end{array}$ \\
\hline SECAGEM Singh & $R^{2}(\%)$ & $D Q M$ & $R^{2}(\%)$ & $D Q M$ & $R^{2}(\%)$ & $D Q M$ & $R^{2}(\%)$ & $D Q M$ \\
\hline 1 & $99,82 \%$ & 0,0210 & $98,93 \%$ & 0,0507 & $99,52 \%$ & 0,0341 & $98,93 \%$ & 0,0507 \\
2 & $95,57 \%$ & 0,1044 & $98,97 \%$ & 0,0508 & $99,65 \%$ & 0,0297 & $98,97 \%$ & 0,0508 \\
3 & $99,93 \%$ & 0,0128 & $99,07 \%$ & 0,0470 & $99,86 \%$ & 0,0182 & $99,07 \%$ & 0,0470 \\
4 & $97,87 \%$ & 0,0749 & $98,71 \%$ & 0,0584 & $99,62 \%$ & 0,0318 & $98,71 \%$ & 0,0584 \\
5 & $99,67 \%$ & 0,0290 & $99,08 \%$ & 0,0485 & $99,87 \%$ & 0,0181 & $99,08 \%$ & 0,0485 \\
6 & $94,04 \%$ & 0,1170 & $98,62 \%$ & 0,0569 & $99,67 \%$ & 0,0277 & $98,62 \%$ & 0,0569 \\
7 & $99,88 \%$ & 0,0174 & $98,81 \%$ & 0,0548 & $99,66 \%$ & 0,0295 & $98,81 \%$ & 0,0548 \\
8 & $97,29 \%$ & 0,0824 & $98,65 \%$ & 0,0583 & $99,66 \%$ & 0,0295 & $98,65 \%$ & 0,0583 \\
9 & $99,54 \%$ & 0,0370 & $98,41 \%$ & 0,0554 & $99,46 \%$ & 0,0385 & $98,49 \%$ & 0,0643 \\
10 & $99,12 \%$ & 0,0577 & $99,12 \%$ & 0,0467 & $99,91 \%$ & 0,0153 & $99,12 \%$ & 0,0467 \\
11 & $98,83 \%$ & 0,0533 & $99,11 \%$ & 0,0465 & $99,81 \%$ & 0,0218 & $99,11 \%$ & 0,0465 \\
\hline
\end{tabular}

Conforme pode ser observado na Tabela 3, verifica-se que o modelo que melhor se ajustou aos dados experimentais, nas diferentes condições de secagem foi o de A proximação da Difusão, pois apresentou os maiores valores de coeficiente de determinação $\left(R^{2}\right)$ superiores a 99\%, e os menores desvios quadráticos médios (DQM). Esses resultados estão semelhantes com os encontrados por Santos et al. (2010), que ao analisarem a cinética de secagem de banana da variedade terra verificaram que o modelo da Aproximação da Difusão ajustou-se aos dados experimentais com elevados valores de coeficientes de determinação e baixo desvio quadrático médio. Concordante com esta observação encontra-se o estudo realizado por SOUSA et al. (2011) que ao avaliarem diferentes equações matemáticas para a cinética de secagem de polpa do oiti verificaram que o modelo de Aproximação da Difusão ajustou-se muito bem aos dados experimentais da secagem.

Os valores dos parâmetros estimados pelo ajuste do modelo da A proximação de Difusão estão apresentados na Tabela 4. 
Tabela 4 - Parâmetros obtidos do modelo de A proximação da Difusão ajustado aos dados de secagem da matriz experimental

\begin{tabular}{cccc}
\hline Ensaio & $a$ & $K$ & $B$ \\
\hline 1 & $-8,39993$ & 0,01135 & 0,92654 \\
2 & $-12,0416$ & 0,02210 & 0,93580 \\
3 & $-8,17303$ & 0,00945 & 0,91043 \\
4 & $-13,6824$ & 0,01920 & 0,93910 \\
5 & $-8,81428$ & 0,01159 & 0,91139 \\
6 & $-16,2013$ & 0,02140 & 0,94260 \\
7 & $-8,79561$ & 0,00893 & 0,91597 \\
8 & $-15,7392$ & 0,01750 & 0,94190 \\
9 & $-12,4480$ & 0,01370 & 0,93370 \\
10 & $-10,2835$ & 0,01600 & 0,92020 \\
11 & $-10,3507$ & 0,01500 & 0,92570 \\
\hline
\end{tabular}

A nalisando os resultados obtidos (Tabela 4), verifica-se que o parâmetro $k$, para o modelo da aproximação da Difusão, que representa a constante da taxa de secagem, aumenta em função do aumento da temperatura e em função do decréscimo da espessura. Resultado semelhante foi encontrado por SANTOS et al. (2010), SILVA et al. (2009), SOUSA et al. (2011) e MELO et al. (2013) ao estudarem a secagem de banana da variedade terra (Musa Sapientum, Linneo), banana maçã, polpa de oiti e polpa do fruto do mandacaru, respectivamente.

\section{CONCLUSÕES}

Mediante os resultados apresentados pode-se concluir que o modelo matemático de A proximação da Difusão representa satisfatoriamente os dados experimentais da secagem da polpa da palma forrageira (Opuntia fícus-indica Mill) com coeficientes de determinação superior a 99\%.

O tempo de secagem diminuiu de forma mais rápida a medida que aumentamos a temperatura e diminuímos a espessura da camada da polpa do broto da palma.

\section{REFERENCIAS BIBLIOGRAFICAS}

ASSOCIATION OF OFFICIAL ANALYTICAL CHEMISTS - AOAC. Official methods ofanalysis. Arlington, $1995.1141 \mathrm{p}$.

CODEX ALIMENTARIUS (FAO/WHO). Codex Standard for Nopal, CODEX STAN 185 1993. CodexAlimentarius, Cidade do México, México, 2005.

FIOREZE, R. - "Princípios de secagem de produtos biológicos". João Pessoa: Editora Universitória/UFPB, 2004. 229 p.

HOFFMANN, W. "Etnobotânica. In: Agroecologia, cultivo e usos da palma forrageira". Roma: FAO, "Produção e Proteção Vegetal". Tradução (SEBRAE/PB), Paper 132, p. 12-14, 1995. MELLO, K.S; FIGUEIREDDO, R. M. F; QUEIROZ, A. J. M; FERNANDES, T. K. S; BEZERRA, M, C, T. "Secagem em camada de Espuma da Polpa do Fruto do Mandacaru: experimentação $e$ 
ajuste de modelos matemáticos". Revista Caatinga, Mossoró, v. 26, n. 2, p. 10-17, abr. - junho., 2013.

MOURA, L.B.; ROCHA, E. M. et al. "Elaboração de produtos alimentícios à base de palma (Opuntiaficus-indica) e do seu fruto". Revista Verde, v. 4, n. 4, 2009.

SAENZ, C.; COSTELL, E. "Rheology of prickly pear (Opuntiaficusindica) concentratedjuices". Engineering and Food. v. 1, p. 133-137, 1990.

SAENZ, C. "Cladodes: a source of dietary fiber". J. PACD. p.117-123, 1997.

SAENZ, C. "Processing technologies: an alternative for cactus pear (Opuntiaspp.) fruits and cladodes". J. of AridEnvironments. v. 46, p. 209-225, 2000.

SANTOS, P.; SILVA, F. S; PORTO, A. G; SILVA, F. T. C; FURTADO, G. F. "Influência de Pré-Tratamentos na Cinética de Secagem em Diferentes Temperaturas de Banana da Variedade Terra (Musa Sapientum, Linneo)". Revista Brasileira de Tecnologia Agroindustrial., v. 04, n. 02: p. 218-234, 2010.

SILVA, A. S; MELO, K. S; ALVES, N. M. C; FERNANDES, T. K. S. F; FARIAS, P. A. "Cinética de Secagem em Camada Fina da Banana Maçã em Secador de Leito Fixo". Revista Brasileira de Produtos A groindustriais, Campina Grande, v. 11, n. 2, p.129-136, 2009.

SOUSA, F. C.; SOUSA, E. P.; SILVA, L. M. M.; MARTINS, J. J. A.; GOMES, J. P.; ROCHA, A. P. T. "Modelagem Matemática para Descrição da Cinética de Secagem de Polpa de Oiti". Revista Educação A grícola Superior. V. 26, n. 2, p. 108-112, 2011.

SOUSA, S. de. "Desenvolvimento experimental de passa de umbu (Spondiastuberose, Arruda Câmara)". (Dissertação). Campina Grande: UFPB, 1999. 98 p.

Yi,X. K.; Wu,W. F.; Zhan,Y. Q.; Li, J. X; Luo, H. P. "Thinlayer drying characteristics and modeling of Chinese jujubes". Mathematical Problems in Engineering, p.1-18, 2012. 